\title{
Child Self-Unbuckling from Automotive Restraints
}

\author{
Lilia Reyes ${ }^{*}$, Joshua Davis², Banku Jairath ${ }^{1}$, Andrew Luo ${ }^{1}$, Jessica Dessick ${ }^{3}$, Zeva Young ${ }^{1}$ \\ and Martha Doxsey ${ }^{1}$
}

${ }^{1}$ Penn State Milton S, Hershey Medical Center, Penn State College of Medicine, Hershey, PA, New York, USA

${ }^{2}$ CEP America/Vituity, Wichita, KS, USA

${ }^{3}$ Jacobi Medical Center, New York, NY, USA

\begin{abstract}
Introduction: Children unbuckling from their own carseats or restraints is a yet unexplored phenomenon that could pose a substantial safety risk. Therefore, we sought to better understand this phenomenon by surveying parents of young children.

Methods: This was a prospective cohort study completed at a single academic institution in 2019. A self-administered survey was given to parents of children up to 6 years old who presented to the emergency department or primary care regarding their experience with their children unbuckling from their carseat.
\end{abstract}

Results: We surveyed 211 parents of 355 children under 6 years old. Among our sample of children less than 6 years of age, $18 \%$ could unbuckle themselves from their child restraint and one in five of those (19\%) while the vehicle is moving.

Conclusion: Over half of children were reported to be under the age of 4 years at the time of first self-unbuckling. This information measures a potential child restraint safety issue that is a public health topic that needs to be addressed.

\section{Keywords}

Carseat, Child safety, Car safety, Infant, Child restraint systems

\section{Introduction}

Nearly 1,000 children per day year in the United States in traffic fatalities [1]. The use of age-appropriate child restraints and seat belts has been effective in reducing morbidity and mortality in motor vehicle collisions $[2,3]$. Many state child passenger safety laws have enforced the use of child restraints, and the 2018 American Academy of Pediatrics (AAP) carseat guidelines were updated to remove an upper age for rear facing carseats, replacing it with "as long as possible" [4]. Despite the marked reduction in mortality and morbidity when young children are buckled in a child restraint, certain barriers to their appropriate use remain. Cost, lack of knowledge, and inconvenience are commonly cited $[5,6]$. Although these studies have highlighted important barriers that need to be addressed to increase the use of car seats, other safety risks, such as children's high-risk activities, have not been addressed.

Appropriate carseats vary by age and size. The 2018 Guidelines of the American Academy of Pediatric recommends children remain in rear facing carseats as long as possible, followed by front facing carseats until 4 years of age, and then booster seats up until 8 years of age (for most average sized children) [4].
To date, no study has assessed the frequency of children unbuckling themselves after being appropriately restrained. Young children may acquire the motor skills to unbuckle from their restraints before developing the cognitive ability to understand the necessity of automotive restraints. This study aimed to identify the age at which a child starts unbuckling, to describe how often and whether unbuckling occurred with the car moving or stopped and to gather information on parental techniques used to address this activity.

\section{Methods}

A 12-question survey, written in English and Spanish, was developed by the research team and modified after

*Corresponding author: Lilia Reyes, Department of Emergency Medicine, Penn State Milton S. Hershey Medical Center, Penn State College of Medicine, Mail Code H043, 500 University Drive, Hershey, PA 17033-0850, USA

Accepted: August 07, 2021

Published online: August 09, 2021

Citation: Reyes L, Davis J, Jairath B, et al. (2021) Child SelfUnbuckling from Automotive Restraints. Clin Pediatr Res 5(1):95-97 
pilot testing. It was distributed to a convenience sample of caregivers of children 6 years old or younger presenting to primary care or a pediatric emergency department in Central Pennsylvania from January-December 2019.

Research staff used the primary care daily schedule or Emergency Department "tracking board" to identify potentially eligible patients. After verifying with the treating provider that the patient was appropriate for the study, the research staff then approached patient to ask if they were willing to complete the survey. If parents/caregivers were willing to participate, research staff gave the survey to caregivers with children less than six years of age. They were given the option of having the questions read to them or to complete the survey on paper. Completed surveys were returned by the parents/caregivers or the nurse to the research team member on the same day of the visit.

The survey asked for information regarding the number of children 6 or less years old living in the household and the current type of safety restraint that was used for each child. Pictures were used to assist caregivers in identifying the types of restraints they used for their children. This study was exempted by the Institutional Review Board. Comparisons are made with Chi-square, and qualitative data was analyzed using iterative coding and grounded theory.

\section{Results}

Data were collected on 353 children 6 years of age and under from 211 surveys (85\% response). Of these children, $18 \%(n=63)$ unbuckled at least once and $19 \%(n=12)$ did so when the car was moving. The median age was 3 years old (range 1-6 years), and 284 (80\%) were under the age of 4 . Of those under 4 years old, $89 \%$ (253/284) were either in a rear or front facing carseat. Out of all children who unbuckled at least once, $54 \%(34 / 63)$ were less than 4 years of age when they first unbuckled. The mean weight was 31 kilograms. Children who unbuckled were $60 \%$ male, with no difference between age of first unbuckling and gender (male 3.3 years old, female 3.4 years old). The most common type of carseat unbuckled from was a front-facing five point harness carseat $(62 \%, 39 / 63)$, and children $<4$ years old in this type of carseat were more likely to unbuckle than those in a front facing carseat $(9 \%$ vs $2 \%, p=0.02)$. A majority $(78 \%)$ of parents allow their children to unbuckle. Qualitative ideas to reduce unbuckling are listed in Table 1.

\section{Discussion}

Among our sample of children less than 6 years of age, $16 \%$ could unbuckle themselves from their child restraint and some while the vehicle is moving. This information demonstrates a potential child restraint safety issue that needs to be addressed. A front-facing carseat is the most common type of carseat children unbuckle themselves from; therefore, our study supports the 2018 AAP Guidelines that children should remain in rear facing carseats as long as possible.

Our study is an example of how children may have the motor capability to perform a task without being at the cognitive stage to understand the danger their action may have. A more familiar example of children not understanding
Table 1: Qualitative suggestions from parents to reduce child selfunbuckling from carseats.

\begin{tabular}{|l|c|}
\hline Idea & n \\
\hline Educate/Reinforce child & 41 \\
\hline Improve carseat design & 17 \\
\hline Educate adults & 7 \\
\hline Appropriate use/size & 6 \\
\hline Distract child & 6 \\
\hline Keep out of reach & 4 \\
\hline Don't show them how & 3 \\
\hline "Keep an eye out" & 1 \\
\hline Get police to "scare" them into going to jail & 1 \\
\hline Button shirt over & 1 \\
\hline Buckle Tighter & 1 \\
\hline Make better carseats cheaper & 1 \\
\hline Punish child & 1 \\
\hline Do not allow it & 1 \\
\hline Duct tape & 1 \\
\hline
\end{tabular}

dangers in their actions is when opening medication bottles [7]. Demonstrated in 1982 that children as young as 23 months could open small aspirin bottles. The identification of the dangers in these childhood actions lead to making child-resistant caps and can also prompt the design of childresistant car restraint latches.

Indeed, parents noted improved design as the second most common way to prevent this issue. For example, a better locking mechanism could prevent the child from unbuckling. One parent noted "Put a hard cover over buttons so that child cannot push them", and another noted "There are alarms to sound for parents to know if belt is undone".

Our study has several limitations. First, it was only a pilot survey study; therefore, effectiveness of potential interventions was not addressed. Second, data was obtained from a limited geographic area; it will be important to examine this problem in other regions of the country. Third, we did not collect sociodemographic information about families; we chose this approach to help ensure a high response rate from parents. Finally, there is potential unreliable recall from the parent as to when their children first unbuckled.

\section{Conclusion}

Among our sample of children less than 6 years of age, $18 \%$ could unbuckle themselves from their child restraint and some while the vehicle is moving. Over half of children were reported to be under the age of 4 years at the time of first self-unbuckling. Given the prevalence of this issue and potential safety hazard, urgent future work on this is needed. Stakeholders, including pediatricians, parents, legislators, researchers, and industry should be involved in identifying a solution to this potential problem.

\section{Funding Source}

None.

\section{Financial Disclosure}

The authors have no financial relationships relevant to this article to disclose. 


\section{Conflicts of Interest}

The authors have no conflicts of interest relevant to this article to disclose.

\section{Ethics}

This study was granted exemption by the Institutional Review Board at Penn State Milton S. Hershey Medical Center. Patients gave verbal consent to complete the survey.

\section{Data Availability}

Data is available from the authors upon reasonable request.

\section{References}

1. Fatality analysis reporting system (FARS) (2019) National Highway Traffic Safety Administration.
2. Arbogast KB, Jermakian JS, Kallan MJ, et al. (2009) Effectiveness of belt positioning booster seats: An updated assessment. Pediatrics 124: 1281-1286.

3. Winston FK, Kallan MJ, Elliott MR, et al. (2007) Effect of booster seat laws on appropriate restraint use by children 4 to 7 years old involved in crashes. Arch pediatr adolesc med 161: 270-275.

4. Durbin DR, Hoffman BD, Council on Injury Violence and Poison Prevention (2018) Child passenger safety. Pediatrics 142: e20182460.

5. Simpson EM, Moll EK, Kassam-Adams N, et al. (2002) Barriers to booster seat use and strategies to increase their use. Pediatrics 110: 729-736.

6. Lee JW, Fitzgerald K, Ebel BE (2003) Lessons for increasing awareness and use of booster seats in a Latino community. Injury prevention 9: 268-269.

7. Kresel JJ, Lovejoy FH, Jr, Boyle WE, et al. (1982) Comparison of large and small child-resistant containers. J Toxicol Clin Toxicol 19: 377-384.

DOI: $10.36959 / 395 / 515$ 